\title{
Photosynthetic parameters of urban greening trees growing on paved land
}

\author{
Xuming Wang ${ }^{(1-2-3)}$, \\ Xiaoke Wang ${ }^{(1-2-4)}$, \\ Yuanyuan Chen ${ }^{(1-2)}$, \\ Graeme P Berlyn ${ }^{(3)}$
}

\begin{abstract}
Two common urban greening trees, ash (Fraxinus chinensis Roxb.) and maple (Acer truncatum Bunge.), were planted in arranged pervious and impervious land pavements to clarify the response in the photosynthetic processes of the urban tree under different types of pavement. Leaf light and $\mathrm{CO}_{2}$ response curves of the net photosynthetic rate were constructed based on in situ measurements in the $4^{\text {th }}$ year after planting, and additional photosynthetic parameters were obtained. The surface temperature and soil temperature significantly increased while the soil moisture significantly decreased in the land pavement, and these changes varied with types of pavement. The light-saturated net photosynthetic rates of both ash and maple, the saturated intercellular $\mathrm{CO}_{2}$ concentration of ash, and the light saturation point, $\mathrm{CO}_{2}$-saturated net photosynthetic rate and maximum carboxylation rate of maple significantly decreased in impervious pavement, indicating that both the capacity of leaf photosynthesis and utilization of high light and $\mathrm{CO}_{2}$ concentrations were significantly reduced by land pavement. The down-regulation of photosynthesis in the impervious pavement was mainly due to the reduction of available soil water. Photosynthetic parameters of maple showed more sensitivity to the land pavement than those of ash. There was less impact from pervious pavement than impervious pavement on the photosynthetic parameters of ash and maple.
\end{abstract}

Keywords: Impervious Pavement, Pervious Pavement, Photosynthesis, Photosynthetic Parameter, Urban Tree cluding roads, squares, and parking lots (Weng 2012), which can provide hostile microenvironments for trees via reducing water infiltration (Liu et al. 2014), increasing surface and soil temperature (Kevern et al. 2012), restricting nutrient input (Yan et al. 2015), aggravating soil compaction (Mullaney et al. 2015C), and inhibiting soil-air gas exchange (Mullaney et al. 2015b). Growing in even adjacent sites bordering this unfavorable habitat, urban trees suffer from restricted growth and are even more vulnerable to death, which eventually limits their ecological benefits (Chen et al. 2017, Mullaney et al. 2015c).

Previous studies have shown that land
(1) State Key Laboratory of Urban and Regional Ecology, Research Center for Eco-Environmental Sciences, Chinese Academy of Sciences, Beijing 100085 (China); (2) University of Chinese Academy of Sciences, Beijing 100049 (China); (3) School of Forestry and Environmental Studies, Yale University, New Haven CT 06511 (USA); (4) Beijing Urban Ecosystem Research Station, Chinese Academy of Sciences, Beijing 100085 (China)

@ Xiaoke Wang (wangxk@rcees.ac.cn)

Received: Aug 02, 2018 - Accepted: May 26, 2019

Citation: Wang X, Wang X, Chen Y, Berlyn GP (2019). Photosynthetic parameters of urban greening trees growing on paved land. iForest 12: 403-410. - doi: 10.3832/ifor2939-012 [online 2019-08-13]

Communicated by: Silvano Fares pavements can lead to drought stress, heat stress, and nutrient stress in urban trees ney et al. 2015a) and can affect plant growth and leaf photosynthesis; specifically, photosynthetic rates, transpiration rates and stomatal conductance (Song et al. 2015, Wang et al. 2019). The effects of land pavement on the physiology of urban trees change with different covering materials and whether the materials are pervious or not (Morgenroth 2011, Mueller \& Day 2005), and the responses of various species and/or years of urban trees on the same land pavement are also different (Chen et al. 2017, Wang et al. 2019). In particular, studies on the effects of pervious materials which are currently widely used for land pavement on the growth of urban trees and their eco-physiological factors are still very limited and have produced inconsistent results (Morgenroth \& Buchan 2009, Volder et al. 2014). Furthermore, in terms of research methods, a few in situ experiments have been directly carried out on different types of pavement within cities (Song et al. 2015); these studies are subject to unavoidable problems, such as inconsistent experimental conditions and surroundings, widely varying soil physicochemical properties, and increased vulnerability to human disturbance.

Photosynthesis is influenced by many ecological factors, including temperature, (Bijoor et al. 2012, Gillner et al. 2015, Mulla- 
light intensity, $\mathrm{CO}_{2}$ concentration, soil moisture, and air humidity (Yamori 2016). Light and $\mathrm{CO}_{2}$ are the indispensable energy source and basic materials for photosynthesis, respectively (Ye 2010). Studies on the photosynthetic response characteristics to light and $\mathrm{CO}_{2}$ can be very instrumental in elucidating the adaptability of plant photosynthetic ecophysiological parameters in changing environments (Danyagri \& Dang 2014). These studies could be very suitable for studying the responses and adaptability of urban tree-related photosynthetic parameters in land pavement environments; however, studies related to these phenomena are scarce (Chen et al. 2016a). Fortunately, advanced instruments allow more photosynthetic parameters to be measured in the field; especially, light and $\mathrm{CO}_{2}$ response curves of the net photosynthetic rate can be fitted by various models to calculate related parameters, which could help to further study the influence of environmental changes on plant photosynthesis (Danyagri \& Dang 2014, Ye 2010).

For this study, a field-simulated experiment with three pavement treatments was designed and established in the urban environment of Beijing, China. The treatments included the control (non-paved, natural land), pervious pavement, and impervious pavement, and two common greening trees, ash (Fraxinus chinensis Roxb.) and maple (Acer truncatum Bunge.), were planted. In this experimental field, Chen et al. (2016a) reported on the growth and photosynthetic characteristics of these seedlings in the $2^{\text {nd }}$ year after planting, but continuous studies for longer durations are not carried out. Wang et al. (2017) reported on the leaf net photosynthetic rate, stomatal conductance, and chlorophyll fluorescence of these trees in the $4^{\text {th }}$ year after planting and analyzed the influence of the main environmental factors, including soil moisture and temperature, but studies on the responses of leaf photosynthetic parameters to light and $\mathrm{CO}_{2}$ under land pavement are lacking, which fails to elucidate the underlying mechanism of the impacts of environmental factors on photosynthesis. In this study, we measured leaf light and $\mathrm{CO}_{2}$ response curves of the net photosynthetic rate of ash and maple in situ in the $4^{\text {th }}$ year after planting. We aimed to investigate the various responses of the photosynthetic parameters in different urban tree species to the pervious pavement and impervious pavement and to further explore the biochemical factors and the underlying mechanism in order to provide references for improving the growth conditions and ecological functions of urban trees.

\section{Materials and methods}

\section{Experimental design}

A field experiment was conducted in a seed test base at Zhangtou Village, Changping District, in a suburb of Beijing, China $\left(40^{\circ} 12^{\prime} \mathrm{N}, 116^{\circ} 08^{\prime} \mathrm{E}\right)$. The area has a typical temperate continental monsoon climate, with four distinct seasons. The mean annual temperature is $12.1{ }^{\circ} \mathrm{C}$, and the mean annual precipitation is $542 \mathrm{~mm}$; the rainfall mostly occurs from June to September. The soil texture at the study site is a sandy loam, the bulk density is $1.5 \mathrm{~g} \mathrm{~cm}^{-3}$, the mean soil organic matter content is $16.4 \mathrm{~g}$ $\mathrm{kg}^{-1}$, the total nitrogen is $0.9 \mathrm{~g} \mathrm{~kg}^{-1}$, the rapidly available phosphorus is $38.1 \mathrm{mg} \mathrm{kg}^{-1}$, the rapidly available potassium is $102.1 \mathrm{mg}$ $\mathrm{kg}^{-1}$, and the $\mathrm{pH}$ value is 8.3 (Chen et al. 2016b).

In April 2012, three types of pavement treatments were established: the control (non-paved, natural land), pervious pavement, and impervious pavement. The pervious pavement and impervious pavement were laid using permeable bricks (permeability $>0.4 \mathrm{~mm} \mathrm{~s}^{-1}, 20 \times 10 \times 6 \mathrm{~cm}$ ) and impermeable bricks (permeability $\approx 0,20 \times 10$ $\times 6 \mathrm{~cm}$ ), respectively. Three blocks were arranged for each type of pavement, which constituted three replicates; each block had the same area of $22.8 \mathrm{~m} \times 17 \mathrm{~m}$. Oneyear-old ash and maple seedlings with consistent height and basal diameter were transplanted. In each block, 18 seedlings of each species were planted in 4 parallel dislocation rows in an east-west direction with a density of $2 \times 2 \mathrm{~m}$. A $20 \times 20 \mathrm{~cm}$ square tree pool was reserved on the corresponding plant point. In August 2015, plant height and basal diameter were measured using a telescopic standard measuring rod (10M, Zhongbao, Shijiazhuang, China) and a vernier caliper (E0551, Endura, Shanghai, China), respectively. The plant height showed pervious pavement $>$ control $>$ impervious pavement $(P<0.05)$ and control > pervious pavement $>$ impervious pavement $(P<0.05)$ for ash and maple, respectively. The basal diameter of maple significantly decreased in pervious and impervious pavements as compared with the control $(P<0.05)$ but not for ash (Wang et al. 2017). In September 2015, the canopy leaf area index ( $\mathrm{LAl}$ ) values were measured by a plant canopy analyzer (LAl-2000 ${ }^{\oplus}$, LICOR, Lincoln, NE, USA). The LAI showed pervious pavement $>$ control $>$ impervious pavement $(P<0.05)$ for ash and the LAl of maple significantly decreased in pervious and impervious pavements as compared with the control $(P<0.05$ - Wang et al. 2017).

\section{Photosynthetic rate measurements in response to changes in light and $\mathrm{CO}_{2}$ exposure}

Net photosynthetic rates were measured using a portable photosynthesis system (LI-6400 ${ }^{\oplus}$ LI-COR, Lincoln, NE, USA) equipped with a fluorescent leaf chamber on sunny windless mornings from 8:30 to 11:30 in 10-23 August, 10-23 September, and 8-21 October 2015. Two healthy plants were selected per block of each species; one mature healthy leaf exposed to the sun at a height of approximately $3 \mathrm{~m}$ for each se- lected plant was subsequently measured. During the measurements, the temperature and relative humidity of the leaf chamber was set to $25 \pm 0.5^{\circ} \mathrm{C}$ and $50 \pm 5 \%$, respectively. To obtain leaf light response curves of the net photosynthetic rate, the leaves were induced with saturation light intensity before the measurements, the reference $\mathrm{CO}_{2}$ concentration was controlled at $400 \mu \mathrm{mol} \mathrm{CO}_{2} \mathrm{~mol}^{-1}$ (Danyagri \& Dang 2014) by using $\mathrm{CO}_{2}$ supplied from a small $\mathrm{CO}_{2}$ cylinder, the photosynthetic photon flux density (PPFD) gradient consisted of 1800, 1500, 1200, 900, 600, 250, 150, 75, and $0 \mu \mathrm{mol}$ photon $\mathrm{m}^{-2} \mathrm{~s}^{-1}$, and the data acquisition time at each PPFD gradient was 3 min. To obtain leaf $\mathrm{CO}_{2}$ response curves of the net photosynthetic rate, the PPFD was set to $1200 \mu \mathrm{mol}$ photon $\mathrm{m}^{-2} \mathrm{~s}^{-1}$ (Yang et al. 2016), and the leaves were induced by the set PPFD for approximately $5 \mathrm{~min}$ before measurement. The $\mathrm{CO}_{2}$ gradient consisted of 400, 300, 200, 100, 50, 400, 600, 800, 1000,1200 , and $1500 \mu \mathrm{mol} \mathrm{CO}_{2} \mathrm{~mol}^{-1}$ by using $\mathrm{CO}_{2}$ supplied from a small $\mathrm{CO}_{2}$ cylinder. The data acquisition time at each $\mathrm{CO}_{2}$ concentration was $3 \mathrm{~min}$.

\section{Measurement of environmental factors}

The pavement surface temperature $\left(T_{p}\right.$, ${ }^{\circ} \mathrm{C}$ ) was measured by the infrared temperature sensor (Optris CS, Optris $\mathrm{GmbH}$, Germany) which was installed vertically on a bracket at the height of $1 \mathrm{~m}$, and a transparent plastic cover was installed at the top of the sensor to prevent the influence of precipitation. The soil temperature $\left(T_{s}\right.$, ${ }^{\circ} \mathrm{C}$ ) at the depth of $20 \mathrm{~cm}$ was measured by the thermocouple wires. The data of $T_{p}$ and $T_{s}$ were recorded every 10 min by using a data acquisition device (CR1000 ${ }^{\oplus}$, Campbell, USA). The soil volume water content (VWCS, \%) was measured by the $\mathrm{ECH}_{2} \mathrm{O}$ monitoring system (Decagon Devices Inc., Pullman, WA, USA) which is composed of an EC-5 soil water content sensor and an EM50 data collector. The EC-5 sensor was buried in the soil at the depth of $20 \mathrm{~cm}$, and the data were recorded every $10 \mathrm{~min}$ by the EM50 data collector. Each sensor was installed in the center of each type of pavement.

\section{Data analysis}

Modified rectangular hyperbolic models (see Appendix 1 in Supplementary material) were used to fit the correlations between net photosynthetic rates and PPFD and $\mathrm{CO}_{2}$ concentrations (Ye 2010). Numerous studies have confirmed that the modified rectangular hyperbolic models are very successful for modeling the responses of photosynthetic rates to PPFD and $\mathrm{CO}_{2}$ concentrations (Ye 2010, Zhu et al. 2017) and for accurately estimating photosynthetic parameters (Wan et al. 2018). From the light response model, we estimated the following parameters: light-saturated net photosynthetic rate $\left(P_{\mathrm{Nmax}}, \mu \mathrm{mol} \mathrm{CO}_{2} \mathrm{~m}^{-2}\right.$ $\left.\mathrm{s}^{-1}\right)$, light saturation point $\left(I_{\mathrm{sat}}, \mu \mathrm{mol}\right.$ photon $\left.\mathrm{m}^{-2} \mathrm{~s}^{-1}\right)$, light compensation point $\left(I_{c}, \mu \mathrm{mol}\right.$ 
photon $\left.\mathrm{m}^{-2} \mathrm{~s}^{-1}\right)$, and dark respiration rate $\left(R_{\mathrm{D}}, \mu \mathrm{mol} \mathrm{CO} \mathrm{CO}^{-2} \mathrm{~s}^{-1}\right)$. In addition, from the $\mathrm{CO}_{2}$ response model, we estimated the following parameters: $\mathrm{CO}_{2}$-saturated net photosynthetic rate $\left(A_{\max }, \mu \mathrm{mol} \mathrm{CO} \mathrm{m}^{-2} \mathrm{~s}^{-1}\right)$, saturated intercellular $\mathrm{CO}_{2}$ concentration ( $C_{\text {isat }}$, $\left.\mu \mathrm{mol} \mathrm{CO}_{2} \mathrm{~mol}^{-1}\right), \mathrm{CO}_{2}$ compensation point $\left(\Gamma, \mu \mathrm{mol} \mathrm{CO}_{2} \mathrm{~mol}^{-1}\right)$, and photorespiration rate $\left(R_{\mathrm{p}}, \mu \mathrm{mol} \mathrm{CO} \mathrm{Cm}^{-2} \mathrm{~s}^{-1}\right)$. Furthermore, biochemical parameters were estimated from the biochemical model (see Appendix 1 Ethier \& Livingston 2004, Farquhar et al. 1980); these parameters included the maximum carboxylation rate $\left(V_{\text {cmax }}, \mu\right.$ mol $\mathrm{CO}_{2}$ $\left.\mathrm{m}^{-2} \mathrm{~s}^{-1}\right)$, maximum electron transport rate $\left(J_{\max }, \mu \mathrm{mol} \mathrm{CO}_{2} \mathrm{~m}^{-2} \mathrm{~s}^{-1}\right)$, and triose phosphate utilization rate (TPU, $\mu \mathrm{mol} \mathrm{CO}_{2} \mathrm{~m}^{-2}$ $\left.\mathrm{s}^{-1}\right)$. The ratio $J_{\max } / V_{c_{\max }}$ was also calculated. The modified rectangular hyperbolic model for light and $\mathrm{CO}_{2}$ concentration responses and the biochemical model for $\mathrm{CO}_{2}$ concentration responses were both parameterized by a software developed by Jianjun Liu and Li Peng (Ye 2010).

The data were analyzed via normal distribution tests (Shapiro-Wilk test) and homogeneity of variance tests (Levene test) before statistical analyses. Post-hoc least significant difference (LSD) tests were performed only when significant differences were detected by ANOVA. The interaction of pavement and time on photosynthetic parameters was determined using re- peated measures of analysis of variance (ANOVA). The differences in environmental factors and photosynthetic parameters among different types of pavement were determined by the paired sample $t$-test and the LSD test, respectively. Data preparation, statistical analysis, and drawings were carried out using Excel ${ }^{T M} 2016$ (Microsoft, Redmond, WA, USA), SPSS ${ }^{\circledR}$ ver. 17.0 (SPSS, Chicago, IL, USA), and Origin ${ }^{\oplus}$ ver. 8.0 (Origin Lab, Hampton, MA, USA) software programs, respectively.

\section{Results}

\section{Environmental factors in the three}

\section{types of pavement}

The daily mean values of $T_{p}, T_{s}$, and VWCS in the three types of pavement for ash and maple from 1 August to 31 October 2015 are shown in Fig. 1. There were consistent influences of the pavements on $T_{\mathrm{p}}$ for ash and maple (Fig. 1a, Fig. 1b). Compared with that on the control pavement, the $T_{p}$ significantly increased on the pervious pavement and the impervious pavement by 1.97 ${ }^{\circ} \mathrm{C}$ and $1.50{ }^{\circ} \mathrm{C}$ for ash $(P<0.05)$ and by 1.93 ${ }^{\circ} \mathrm{C}$ and $1.69{ }^{\circ} \mathrm{C}$ for maple $(P<0.05)$, respectively. The $T_{\mathrm{p}}$ on the pervious pavement significantly increased by 0.46 and $0.23{ }^{\circ} \mathrm{C}$ for ash and maple, respectively $(P<0.05)$, as compared with that on the impervious pavement. The influences of the pave- ments on $T_{\mathrm{s}}$ for ash and maple were different (Fig. 1C, Fig. 1d). For ash, the $T_{\mathrm{s}}$ was 0.87 and $0.36{ }^{\circ} \mathrm{C}$ higher in the impervious pavement and the pervious pavement than in the control and was $0.51^{\circ} \mathrm{C}$ higher in the impervious pavement than in the pervious pavement $(P<0.05)$. For maple, the $T_{\mathrm{s}}$ was 1.60 and $1.19^{\circ} \mathrm{C}$ higher in the pervious pavement and the impervious pavement than in the control, and was $0.40{ }^{\circ} \mathrm{C}$ higher in the pervious pavement than in the impervious pavement $(P<0.05)$. Because of the low permeability, the VWCS in the impervious pavement was lowest in the three types of pavement for both ash and maple $(P<0.05)$ (Fig. 1e, Fig. 1f). Compared with that in the control pavement, the VWCS significantly decreased in the impervious pavement and the pervious pavement by $11.3 \%$ and $6.6 \%$ for ash $(P<0.05)$ and by $4.3 \%$ and $1.3 \%$ for maple $(P<0.05)$, respectively. The VWCS in the impervious pavement significantly decreased by $4.7 \%$ and $3.1 \%$ for ash and maple, respectively $(P<0.05)$, as compared with that in the pervious pavement.

\section{Parameters from light response curves}

The coefficients of determination $\left(R^{2}\right)$ that fit the leaf light response curve of the net photosynthetic rate by the modified rectangular hyperbolic model were all greater than $0.95(P<0.01)$. The pavement and time showed significant effects on the
Fig. 1 - Daily mean values of surface temperature $\left(T_{p}\right.$, $\left.{ }^{\circ} \mathrm{C}\right)$, soil temperature $\left(T_{s}\right.$,

$\left.{ }^{\circ} \mathrm{C}\right)$, and soil volume water content (VWCS, \%) in the three types of pavement for ash (a, c, and e) and maple (b, d, and f).

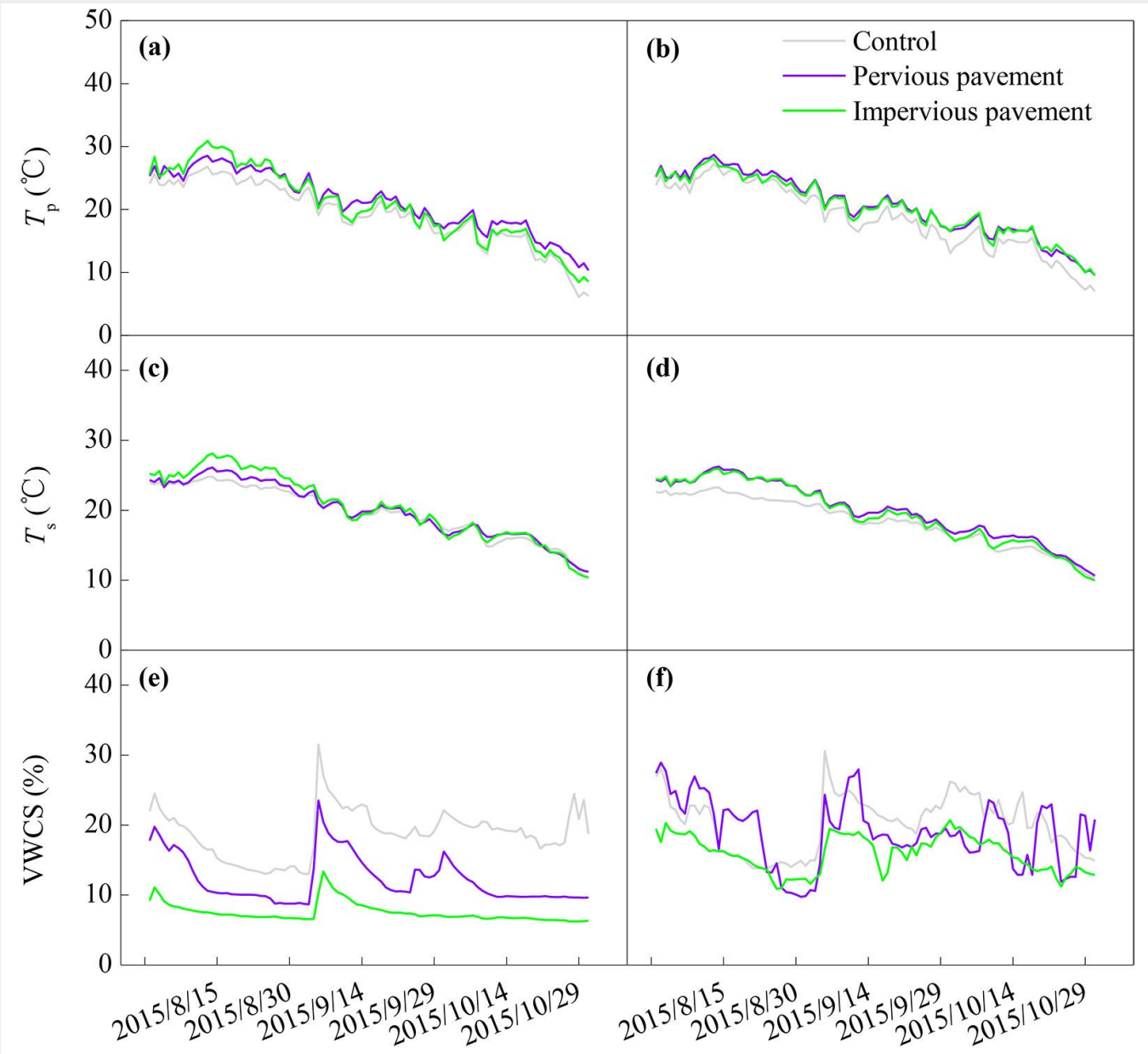




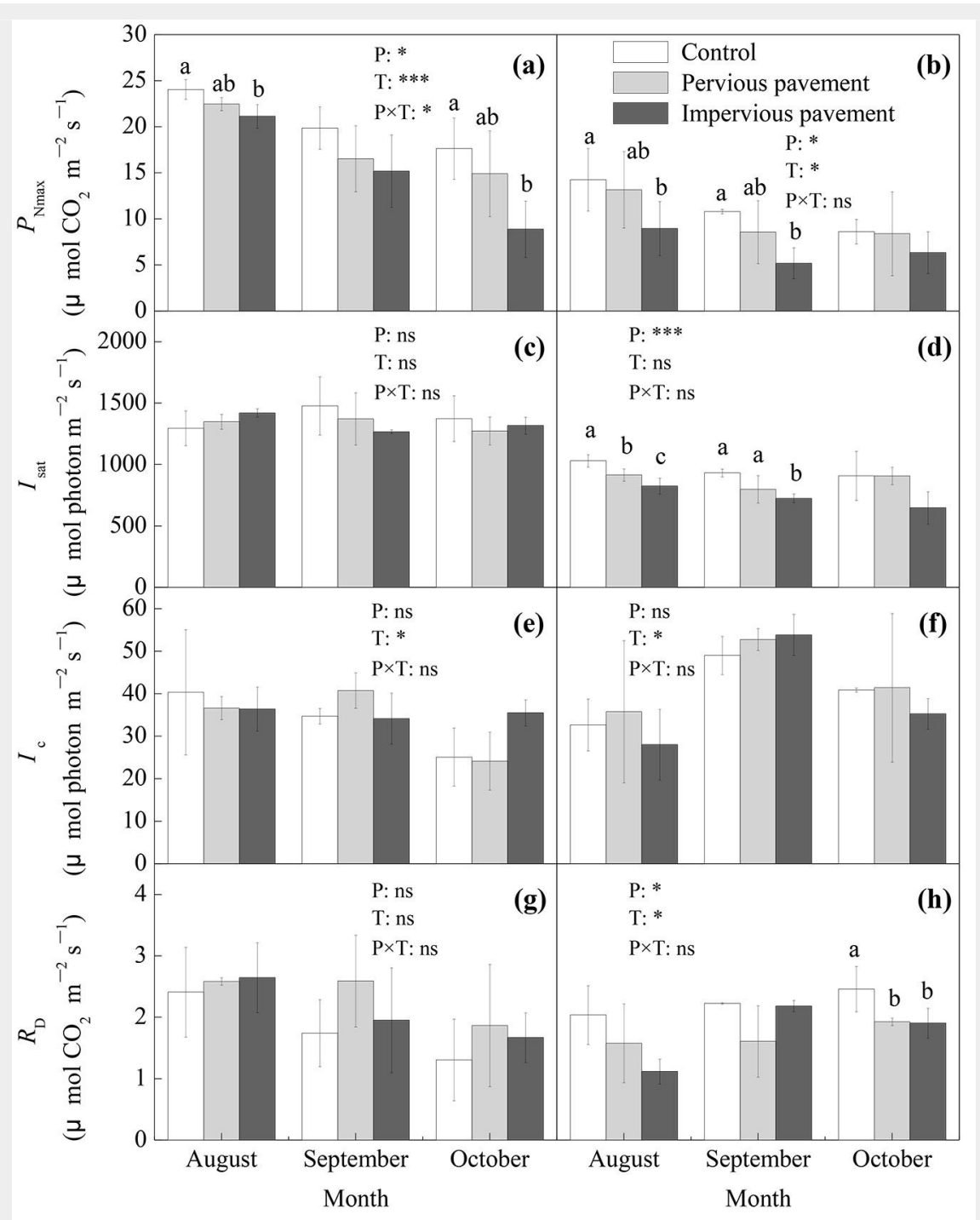

Fig. 2 - Light-saturated net photosynthetic rate $\left(P_{\mathrm{Nmax}}\right)$, light saturation point $\left(I_{\text {sat }}\right)$, light compensation point $\left(I_{c}\right)$, and dark respiration rate $\left(R_{D}\right)$ of ash $(a, c, e$, and $g$ ) and maple (b, $d, f$, and $h$ ) estimated from photosynthetic light response curves under different types of pavement. The data are the averages $\pm S D(n=6)$; different lowercase letters indicate significant differences among the different types of pavement in the same month (LSD test, $P<0.05$ ). The results of the repeated measurements ANOVA are also reported; asterisks show the significance of factors (P: pavement; T: time) and their interaction. $(* * *): P<0.001 ;(*): P<0.05 ;(n s): P>0.05$.

$P_{\mathrm{N} \max }$ of both ash and maple ( $P<0.05$ - Fig. and $49.6 \%$ for ash in August and October, $2 a$, Fig. 2b). Compared with that on the respectively $(P<0.05)$ and by $37.2 \%$ and control pavement, the $P_{\mathrm{N} \max }$ on impervious $52.0 \%$ for maple in August and September, pavement significantly decreased by $12.1 \%$ respectively $(P<0.05-$ Fig. $2 a$, Fig. 2b).

Tab. 1 - Pearson's correlation coefficient between environmental factors and $P_{\mathrm{N} \max }$, and $A_{\max }$ of ash and maple $(n=9) .(* *): P<0.01 ;(*): P<0.05$. No asterisks indicate the absence of any significant relationship.

\begin{tabular}{llllllll}
\hline \multirow{2}{*}{ Parameter } & \multirow{2}{*}{ Month } & Ash & \multicolumn{5}{c}{ Maple } \\
\cline { 3 - 7 } & & $T_{\mathrm{p}}$ & $T_{\mathrm{s}}$ & VWCS & $T_{\mathrm{p}}$ & $T_{\mathrm{s}}$ & VWCS \\
\hline$P_{\text {Nmax }}$ & August & -0.659 & -0.664 & $0.669^{*}$ & -0.179 & -0.337 & 0.418 \\
& September & -0.422 & -0.451 & 0.573 & -0.571 & -0.434 & $0.777^{*}$ \\
& October & -0.082 & 0.233 & $0.699^{*}$ & -0.233 & 0.050 & 0.336 \\
\multirow{2}{*}{$A_{\max }$} & August & -0.395 & -0.284 & 0.341 & 0.197 & -0.099 & $0.841^{* *}$ \\
& September & -0.485 & -0.383 & 0.547 & -0.511 & -0.311 & $0.885^{* *}$ \\
& October & $-0.790^{*}$ & $-0.676^{*}$ & 0.499 & 0.034 & 0.411 & 0.191 \\
\hline
\end{tabular}

There were significantly positive relationships between $P_{\mathrm{Nmax}}$ and VWCS for ash in August and October and maple in September $(P<0.05)$ but no significant relationship was found between $P_{N \max }$ and $T_{\mathrm{p}}$, and $T_{\mathrm{s}}$ for both ash and maple (Tab. 1). The pavement exerted significant influence on the $I_{\text {sat }}$ of maple $(P<0.05)$, the $I_{\text {sat }}$ of maple was significantly lower on the impervious pavement than both on the pervious and control pavements in August $(P<0.05)$ and September $(P<0.05)$ and was significantly lower on the pervious pavement than on the control pavement in August $(P<0.05)$; however, there was no significant difference in $I_{\text {sat }}$ between different pavements in any month for ash (Fig. 2c, Fig. 2d). The $I_{c}$ of ash and maple exhibited no significant differences between different pavements for each measurement (Fig. 2e, Fig. 2f). The $R_{D}$ of maple on the control pavement was significantly higher than that on the other pavements in October $(P<0.05)$, while the $R_{D}$ of ash showed no significant difference between different pavements in any month (Fig. 2g, Fig. 2h).

\section{Parameters from $\mathrm{CO}_{2}$ response curves}

The coefficients of determination $\left(R^{2}\right)$ in response to fitting the net photosynthetic rate response curves to $\mathrm{CO}_{2}$ were all greater than $0.95(P<0.01)$. The pavement and time but not their interactions showed significant effects on the $A_{\max }$ of both ash and maple ( $P<0.05$ - Fig. 3a, Fig. 3b). Compared with that on the control pavement, the $A_{\max }$ on the pervious pavement significantly decreased by $23.0 \%$ for ash in October $(P<0.05)$ and on the impervious pavement decreased by $39.8 \%$ for maple in September $(P<0.05)$. Compared with that on the pervious pavement, $A_{\max }$ on the impervious pavement significantly decreased by $32.1 \%$ and $35.8 \%$ for maple in August $(P<0.05)$ and September $(P<0.05)$, respectively (Fig. 3a, Fig. 3b). There were significant negative relationships between $A_{\max }$ and $T_{p}$, and $T_{s}$ for ash in October $(P<0.05)$ and positive relationships between $A_{\max }$ and VWCS for maple in August and September $(P<0.05-$ Tab. 1$)$. There were significant influences of pavement and time but not their interactions on the $C_{\text {isat }}$ of ash $(P<0.05)$, the $C_{\text {isat }}$ of ash was significantly lower on the impervious pavement than on the other pavements in August and September $(P<0.05)$, and the $C_{\text {isat }}$ of maple was lower on the pervious pavement than on the other pavements in September $(P<0.05$ - Fig. 3c, Fig. 3d). The differences in $\Gamma$ between pavement treatments varied with measurements for maple, while there was no significant difference for ash (Fig. 3e, Fig. $3 f$ ). The pavement and time and their interactions significantly impacted the $R_{\mathrm{p}}$ of ash $(P<0.05)$, the $R_{p}$ of ash was significantly lower on the pervious pavement than on the impervious pavement in August $(P<0.05)$, but the opposite case occurred in September $(P<0.05)$ and October $(P<0.05)$. The $R_{p}$ of ash was higher on the 


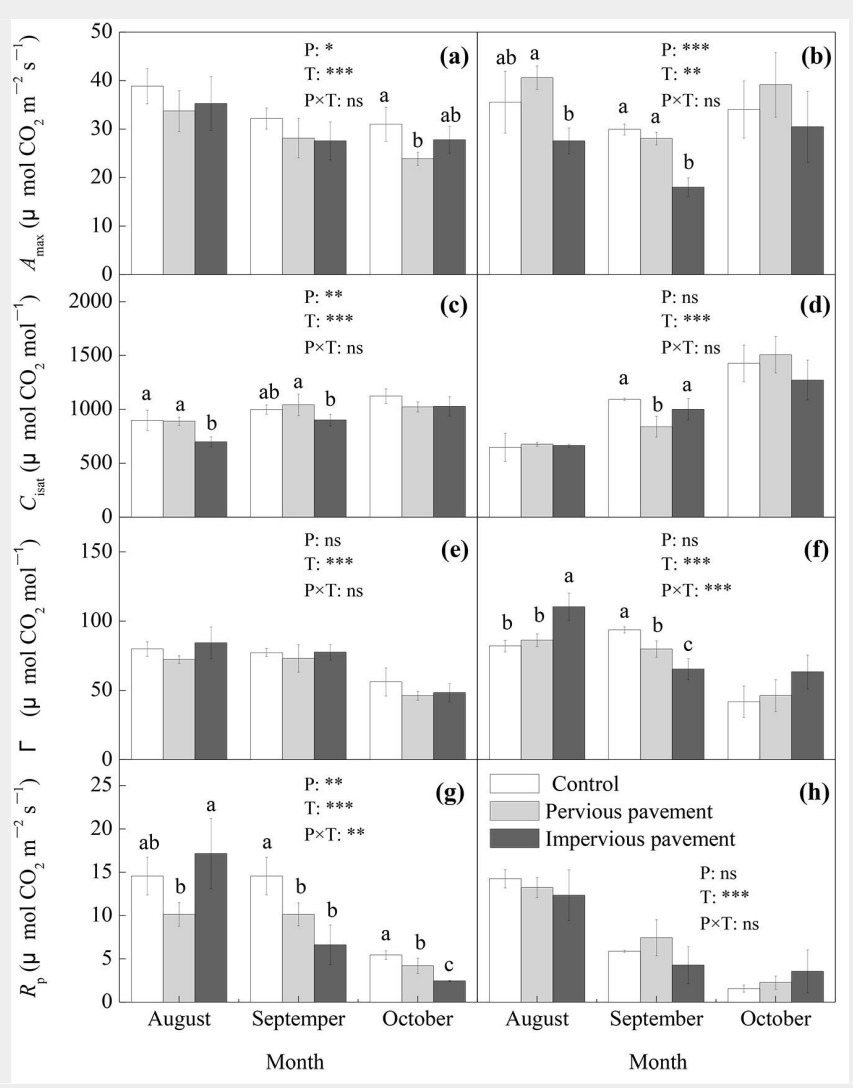

Fig. $3-\mathrm{CO}_{2}$-saturated net photosynthetic rate $\left(A_{\max }\right)$, saturated intercellular $\mathrm{CO}_{2}$ concentration $\left(C_{\text {isat }}\right), \mathrm{CO}_{2}$ compensation point $(\Gamma)$, and photorespiration rate $\left(R_{\mathrm{p}}\right)$ of ash (a, c, e, and g) and maple (b, d, f, and h) estimated from photosynthetic $\mathrm{CO}_{2}$ response curves under different types of pavement. The data are the averages $\pm S D(n=6)$; different lowercase letters indicate significant differences among the different types of pavement in the same month (LSD test, $P<0.05$ ). The results of the repeated measurements ANOVA are also reported; asterisks show the significance of factors ( $P$ : pavement; $T$ : time) and their interaction. $(* * *): P<0.001 ;(* *): P<0.01 ;(*): P<0.05 ;(n s)$ : $P>0.05$.

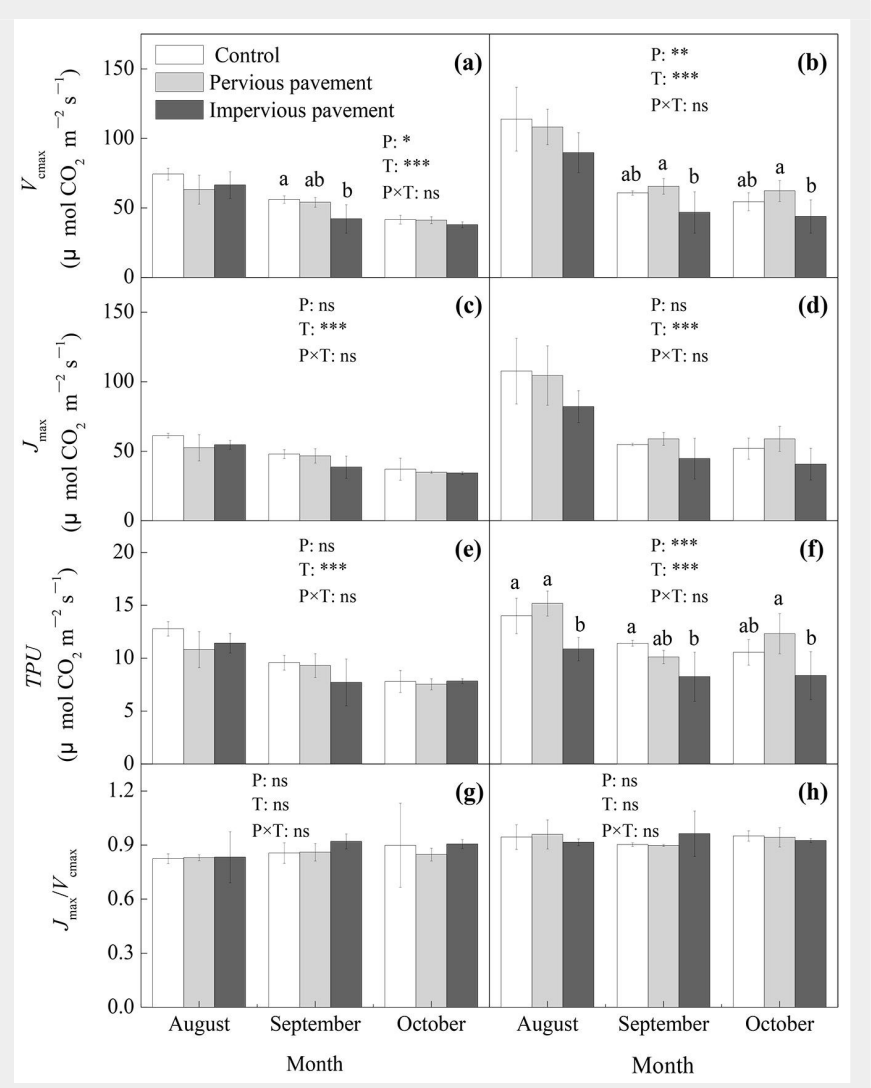

Fig. 4 - Maximum carboxylation rate $\left(V_{c \max }\right)$, maximum electron transport rate $\left(J_{\max }\right)$, triose phosphate utilization rate (TPU), and $J_{\max } / V_{\text {cmax }}$ of ash (a, c, e, and g) and maple (b, d, f, and h) estimated from photosynthetic $\mathrm{CO}_{2}$ response curves under different types of pavement. The data are the averages \pm SD $(n=$ 6 ); different lowercase letters indicate significant differences among the different types of pavement in the same month (LSD test, $P<0.05$ ). The results of the repeated measurements ANOVA are also reported; asterisks show the significance of factors ( $\mathrm{P}$ : pavement; $\mathrm{T}$ : time) and their interaction. $(* * *)$ : $P<0.001 ;(* *): P<0.01 ;(*): P<0.05 ;(n s): P>0.05$. control pavement than on the other pavements in September and October $(P<0.05)$. There was no significant difference in $R_{p}$ between different pavements in any month for maple (Fig. 3g, Fig. 3h).

\section{Biochemical parameters from $\mathrm{CO}_{2}$ response curves}

The pavement and time but not their interactions showed significant effects on the $V_{c \max }$ of both ash and maple $(P<0.05)$ (Fig. 4a, Fig. 4b). The $V_{\text {cmax }}$ was significantly lower on the impervious pavement than on the control pavement for ash in September $(P<0.05)$ and was significantly lower on the impervious pavement than on the pervious pavement for maple in both September and October ( $P<0.05$ - Fig. 4a, Fig. 4b). The pavement and time but not their interactions significantly impacted on the TPU of maple $(P<0.05)$, the TPU of maple was significantly lower on the impervious pavement than on the control pavement in August $(P<0.05)$ and September $(P<0.05)$ and was significantly lower on the impervious pavement than on the pervious pavement in October $(P<0.05)$. The TPU of ash exhibited no significant difference between any of the pavements (Fig. 4e, Fig. 4f). There was no significant difference in the $J_{\max }$ or $J_{\max } / V_{\text {cmax }}$ ratio between any of the pavement treatments for either ash or maple (Fig. 4C, Fig. 4d, Fig. 4g, Fig. 4h).

\section{Discussion}

Impacts of land pavement on the

photosynthesis of plants

The pavement-induced decreases in photosynthesis are mainly attributed to the increased air and soil temperature and the decreased air relative humidity and soil moisture content (Song et al. 2015, Wang et al. 2019). We found on the impervious pavement the $T_{\mathrm{p}}$ and $T_{\mathrm{s}}$ significantly increased and the VWCS significantly decreased for both ash and maple (Fig. 1), which could be credibly deduced that the effects of higher temperature and less available soil water on photosynthesis occurred in the impervious pavement. There were significantly positive relationships be- tween $P_{\mathrm{Nmax}}$ and VWCS but not $T_{\mathrm{p}}$, and $T_{\mathrm{s}}$ for both ash and maple (Tab. 1), indicating that $P_{\mathrm{Nmax}}$ decreased under pavement treatments due to the reduction in soil moisture but not temperatures. The possible reason was that temperature was not significantly changed by pavement due to the strong shading effects of high leaf area index of ash and maple after their canopy closed (Wang et al. 2017).

Photosynthesis is regulated by both stomatal and biochemical factors (Lenz et al. 2010). The decrease of stomatal conductance is one of the reasons that the decline of photosynthesis caused by land pavement (Song et al. 2015, Wang et al. 2019). Impervious pavement decreased water amount available for trees, and leaf stomatal conductance was reduced (Wang et al. 2017). In the biochemical aspect, plant photosynthesis is a complex physiological process and in general mainly consists of three steps: (1) primary reactions, including light absorption, transmission and conversion; (2) electron transport, photophosphorylation, and the formation of biologi- 
cal chemical energy (ATP and NADPH); and (3) carbon assimilation, which is the conversion of active chemical energy into stable chemical energy (fixed $\mathrm{CO}_{2}$, formation of sugars - Pan et al. 2012). The photosynthesis/photosynthetic rate would be inevitably altered if one step is affected. Inten sive measurements of the physiological process of photosynthesis could help in understanding the relationships between environmental changes and photosynthesis. A series of parameters can be obtained from the light and $\mathrm{CO}_{2}$ response curves of the photosynthetic rates curves for charac terizing photosynthetic process (Danyagri \& Dang 2014, Ye 2010).

In the first step of the photosynthetic process, leaf response to light intensity is critical. We have assessed the initial slope of the light-response curve and did not find any significant difference between pavement treatments, indicating under low light intensity the photosynthesis was not significantly influenced by pavement (Zhu et al. 2017). But we found the $I_{\text {sat }}$ of maple significantly decreased on the impervious pavement (Fig. 2), implying that the utilization ability of high light intensity was reduced (Wan et al. 2018) and the leaf may be more susceptible to photoinhibition, which was supported by Wang et al. (2019) based on chlorophyll fluorescence measurements. Meanwhile, the $I_{c}$ of maple showed no significant change on the impervious pavement (Fig. 2), indicating that in the daytime the period of effective net photosynthesis would be reduced ( $\mathrm{Wu}$ et al. 2008), which would ultimately restrict the light harvesting.

In the second step of photosynthetic processes, electron transport plays a key role and can be characterized by the $J_{\max }$ in the present study. However, there was no significant difference of $J_{\max }$ between pavement treatments for both ash and maple (Fig. 4). Even some previous studies have found that the $J_{\max }$ was significantly inhibited by land pavement and/or drought ( $\mathrm{Li}$ mousin et al. 2010, Wang et al. 2019).

In the third step of the photosynthetic process, the carbon assimilation pathway of $C_{3}$ plants can be divided into three stages: carboxylation, reduction, and regeneration stages. The $V_{c \max }$ is the maximum carboxylation reaction rate catalyzed by the ribulose-1,5-diphosphate carboxylase/oxygenase (Rubisco - Farquhar et al. 1980). The $V_{\text {cmax }}$ and $A_{\max }$ of maple significantly decreased on the impervious pavement (Fig. 3, Fig. 4), indicating that the photosynthetic enzyme activity and the utilization ability of high $\mathrm{CO}_{2}$ concentrations of maple might be reduced. The $V_{c \max }$ is primarily affected by Rubisco content and activity, which is positively related to the leaf nitrogen $(\mathrm{N})$ content and the amount of leaf $\mathrm{N}$ invested in the Rubisco (Walker et al. 2014). Under land pavements litter return to the soil is prevented, thereby decreasing nutrient supply to leaf $\mathrm{N}$. Moreover, the decreased available soil water and en- hanced soil compaction inhibit root nutritional uptake, all result in a smaller allocation of leaf $\mathrm{N}$ to Rubisco (Warren \& Adams 2004). Triose phosphates, including glyceraldehyde 3-phosphate (PGAld), are products of the reduction stage and serve as the renewable material for ribulose-1,5diphosphate (RuBP) in the regeneration phase (Pan et al. 2012). The TPU of maple decreased significantly on the impervious pavement (Fig. 4). Meanwhile, there was no significant difference of $J_{\max }$ and the $J_{\max } / V_{\text {cmax }}$ ratio between pavement treatments for both ash and maple (Fig. 4), indicating that the functional balance between the electron transport and Rubisco ability of leaves was not broken. From these results, carbon assimilation rate seems to be limited by TPU rather than the rate of RuBP regeneration by $J_{\max }$. This may be because of the phosphorus ( $P$ ) limitation and concomitant decrement of mycorrhizal activity under drought stress and nutrient scarcity (Garg et al. 2004, Smith \& Smith 2011) that may be caused by land pavement. Another possible explanation is that decreasing leaf P substantially decreases the sensitivity of $V_{\text {cmax }}$ to leaf $N$ (Walker et al. 2014), implying that lower leaf $\mathrm{P}$ limits RuBP regeneration (Reich et al. 2009). Some previous studies have found a decrement of soil $P$ and leaf $P$ concentration in trees under urban environment or land pavement (Cekstere \& Osvalde 2013, Ferrini \& Baietto 2007).

Apart from the three steps of the photosynthetic process, photorespiration $\left(R_{p}\right)$ is an important process influencing the net photosynthetic rate of plants. Our results showed that the $R_{\mathrm{p}}$ of ash decreased significantly in both pervious pavement and impervious pavement except in August (Fig. 3). Rubisco activity is closely related to the capacity of photorespiration (Farquhar et al. 1980) and also mediates the response of oxygen resulting in a release of $\mathrm{CO}_{2}$ as oxygenation. In the sense of decreased $V_{c \max }$ in the impervious pavement for ash, the $R_{p}$ should decrease. The simultaneous decrease in $V_{\text {cmax }}$ and $R_{p}$ in urban tree saplings under drought and pavement environment was also found in our previous study (Wang et al. 2019). The decrease of photorespiration could inhibit its protection mechanism for photosynthesis under high light and temperature conditions, that is using excess energy to avoid the damage of photosynthetic apparatus and decreases in the photosynthetic electron transport rate and light phosphorylation (Noguchi \& Yoshida 2008). In addition to consuming excess energy, photorespiration can release phosphate $(\mathrm{Pi})$ groups that could be combined with PGAld; this phenomenon could mitigate the restrictions of the electron transport and photophosphorylation caused by the temporary deficit of $\mathrm{Pi}$ (Wang et al. 2014).

\section{Different impacts between pervious and impervious pavements} Generally, pervious pavement can allevi- ate impervious pavement-induced decreases in water infiltration through the surface into the subsoil. Former studies reported higher infiltration rates and higher soil water contents under pervious pavement than under impervious pavement (Chen et al. 2016a). Our results also showed that the VWCS was significantly higher under pervious pavement than under impervious pavement for both ash and maple (Fig. 1). However, pervious pavement contains more pores filled with air, which prevents heat from transferring downward; as such, the surface temperature increases quickly, resulting in higher surface temperatures on pervious pavement than on impervious pavement (Chen et al. 2017), this phenomenon was also observed in the present study (Fig. 1). Due to the complex effects of pervious pavement on the hydrothermal environment for trees, related studies reported inconsistent results such as pervious pavements have adverse or no significant ameliorative effects on tree growth (Morgenroth \& Buchan 2009, Viswanathan et al. 2011). Field measurements showed that, compared with unpaved land, pervious pavement, as well as impervious pavement, inhibits leaf net photosynthetic rates (Chen et al. 2016a). Those inhibitions may occur when the trees are young and could not provide significant shading effects on paved land; in return, the trees suffer from a harsh, hotter environment. In the present study where tree canopy was approaching to closure, the $P_{N \max }$ and $A_{\max }$ of ash and maple did not significantly reduce on the pervious pavement but significantly reduced on the impervious pavement (Fig. 2, Fig. 3). This may be due to the difference in available soil water between pavement treatments, since the limited decrement of VWCS in pervious pavement did not decline below the tolerance of these two tree species and thus could not exert significant effects on their photosynthesis. Although there were significant impacts of the pervious pavement on some photosynthetic parameters (e.g., $R_{\mathrm{p}}$ for ash - Fig. 3), more parameters were impacted by the impervious pavement than by the pervious pavement because of less available soil water under the former.

\section{Influences of tree species}

In our study, the impacts of land pavement on photosynthesis/photosynthetic parameters varied with the two tree species. Photosynthetic parameters such as $I_{\text {sat }}, A_{\max }, V_{\text {cmax }}$, and TPU were significantly influenced by land pavement (especially impervious pavement) for maple more than for ash (Fig. 2, Fig. 3, Fig. 4). This finding indicated that maple showed more sensitivity than did ash on the pavement. This phenomenon may be due to the interaction between environmental factors and tree species and the different physiological features of ash and maple. We documented that the $T_{\mathrm{s}}$ was highest in the impervious 
pavement for ash while in the pervious pavement for maple (Fig. 1), which was also documented in the study of Chen et al. (2017), and this interaction might make the effects of land pavement on photosynthetic processes for different tree species appear more complex. Apart from the different thermal environments, there is a noticeable difference in physiological feature between the ash and maple, the former is ring-porous wood and the latter is diffuseporous wood. Ring-porous wood has a stronger maximum water transport capacity than does diffuse-porous wood; this ability can ensure water supply better (Steppe \& Lemeur 2007). The latter study pointed out that ash has higher stomatal conductance and leaf transpiration and more obvious variations between pavement treatments than maple (Wang et al. 2017), which seems to be the main cause of much more difference in VWCS between pavement treatments in ash in comparison to maple. Although ring-porous wood is more susceptible to producing cavitation and embolisms under water stress, compared with diffuse-porous wood, this type of wood species have a stronger stomatal regulatory ability that can reduce more effectively the threat of embolisms (Taneda \& Sperry 2008). Thus, ash trees can ensure better water supplies than maple, even under unfavorable soil water conditions caused by impervious pavement. Overall, land pavement-induced soil moisture decreases could impact maple more than ash.

\section{Conclusions}

Urban trees growing on paved land experience hostile environments, e.g., hot surfaces, soil moisture deficit, and soil compaction. Plant responses to stress initially manifest in physiological characteristics. The results of this study showed that temperature significantly increased and the soil moisture significantly decreased in the land pavement, and these changes varied between impervious pavement and pervious pavement. The $P_{\mathrm{N} \max }$ of both ash and maple significantly decreased on the impervious pavement, mainly due to the reduction of available soil water. Different changes in photosynthetic parameters were found in different tree species. For ash, $C_{\text {isat }}$ decreased significantly, indicating that the utilization ability for high concentrations of $\mathrm{CO}_{2}$ decreased, $\mathrm{R}_{\mathrm{p}}$ significantly decreased, which inhibited the protection mechanism. For maple, $I_{\text {sat }}$ decreased significantly, such that photoinhibition would occur more easily; $A_{\max }$ decreased significantly, inhibiting the photosynthetic electron transport and phosphorylation activity; $V_{c \max }$ was significantly reduced, implying that the Rubisco activity was influenced; and the TPU significantly decreased, which inhibited RuBP regeneration. The significant decreases in the $I_{\text {sat }}, A_{\max }$, and $V_{\text {cmax }}$ of maple and in the $C_{\text {isat }}$ of ash on the impervious pavement indicate that the capacity of leaf photosynthesis and the utilization of high light and $\mathrm{CO}_{2}$ concentrations were significantly reduced by land pavement. Overall, land pavement affected the photosynthetic parameters of maple more than those of ash, implying that maple showed more sensitivity. Compared with that from the impervious pavement, there was less influence from the pervious pavement on the photosynthetic parameters of ash and maple, suggesting pervious materials are more suitable for land pavement where trees will be planted.

\section{Acknowledgements}

This study was supported by the National Natural Science Foundation of China (41571053, 71533005), the National Key R\&D Program of China (2016YFC0503004), and the State Scholarship Fund of China Scholarship Council (201804910455).

\section{References}

Bijoor NS, McCarthy HR, Zhang D, Pataki DE (2012). Water sources of urban trees in the Los Angeles metropolitan area. Urban Ecosystems 15: 195-214. - doi: 10.1007/s11252-011-0196-1

Cekstere G, Osvalde A (2013). A study of chemical characteristics of soil in relation to street trees status in Riga (Latvia). Urban Forestry and Urban Greening 12: 69-78. - doi: 10.1016/j. ufug.2012.09.004

Chen B, Adimo OA, Bao Z (2009). Assessment of aesthetic quality and multiple functions of urban green space from the users' perspective: the case of Hangzhou Flower Garden, China. Landscape and Urban Planning 93: 76-82. - doi: 10.1016/j.landurbplan.2009.06.001

Chen Y, Jiang B, Wang X, Li L (2016a). Responses of growth and photosynthetic characteristics of Acer truncatum seedlings to hardening pavements. Chinese Journal of Ecology 35(12): 32583265. [in Chinese]

Chen Y, Wang X, Jiang B, Yang N, Li L (2016b). Pavement induced soil warming accelerates leaf budburst of ash trees. Urban Forestry and Urban Greening 16: 36-42. - doi: 10.1016/j.ufug. 2016.01.014

Chen $\mathrm{Y}$, Wang $\mathrm{X}$, Jiang $\mathrm{B}$, Wen $\mathrm{Z}$, Yang $\mathrm{N}$, Li L (2017). Tree survival and growth are impacted by increased surface temperature on paved land. Landscape and Urban Planning 162: 68-79. doi: 10.1016/j.landurbplan.2017.02.001

Danyagri G, Dang Q (2014). Effects of elevated $\left[\mathrm{CO}_{2}\right]$ and soil temperature on photosynthetic responses of mountain maple (Acer spicatum L.) seedlings to light. Environmental and Experimental Botany 107: 64-70. - doi: 10.1016/j.env expbot.2014.05.010

Ethier GJ, Livingston NJ (2004). On the need to incorporate sensitivity to $\mathrm{CO}_{2}$ transfer conductance into the Farquhar-von Caemmerer-Berry leaf photosynthesis model. Plant, Cell and Environment 27: 137-153. - doi: 10.1111/j.1365-3040. 2004.01140.x

Farquhar GD, Von Caemmerer S, Berry JA (1980). A biochemical model of photosynthetic $\mathrm{CO}_{2}$ assimilation in leaves of $C_{3}$ species. Planta 149 (1): 78-90. - doi: 10.1007/BFo0386231

Ferrini F, Baietto M (2007). Effect of compostamended backfill and paved surface on leaf parameters and physiology of Norway maple
(Acer platanoides L.). Arboriculture and Urban Forestry 33 (6): 386-391.

Garg BK, Burman U, Kathju S (2004). The influence of phosphorus nutrition on the physiological response of moth bean genotypes to drought. Journal of Plant Nutrition and Soil Science 167 (4): 503-508. - doi: 10.1002/jpln.2003 20368

Gillner S, Vogt J, Tharang A, Dettmanna S, Roloffd A (2015). Role of street trees in mitigating effects of heat and drought at highly sealed urban sites. Landscape and Urban Planning 143: 33-42. - doi: 10.1016/j.landurbplan.2015.06.005

Kevern JT, Haselbach L, Schaefer VR (2012). Hot weather comparative heat balances in pervious concrete and impervious concrete pavement systems. Journal of Heat Island Institute International 7 (2): 231-237. [online] URL: http:// www.heat-island.jp/web journal/HI2009Conf/ pdf/33.pdf

Kiran GS, Kinnary S (2011). Carbon sequestration by urban trees on roadsides of Vadodara city. International Journal of Engineering Science and Technology 3 (4): 3066-3070. - doi: 10.4314/ ijest.v3i4.68557

Lenz KE, Host GE, Roskoski K, Noormets A, Sober A, Karnosky DF (2010). Analysis of a Farquhar-von Caemmerer-Berry leaf-level photosynthetic rate model for Populus tremuloides in the context of modeling and measurement limitations. Environmental Pollution 158 (4): 10151022. - doi: 10.1016/j.envpol.2009.08.004

Limousin JM, Misson L, Lavoir AV, Martin NK, Rambal S (2010). Do photosynthetic limitations of evergreen Quercus ilex leaves change with long-term increased drought severity? Plant, Cell and Environment 33: 863-875. - doi: 10.1111/j. 1365-3040.2009.02112.x

Liu W, Chen W, Peng C (2014). Assessing the effectiveness of green infrastructures on urban flooding reduction: a community scale study. Ecological Modelling 291: 6-14. - doi: 10.1016/j. ecolmodel.2014.07.012

Livesley SJ, McPherson GM, Calfapietra C (2016). The urban forest and ecosystem services: impacts on urban water, heat, and pollution cycles at the tree, street, and city Scale. Journal of Environmental Quality 45: 119-124. - doi: 10.2134/jeq2015.11.0567

Morgenroth J, Buchan GD (2009). Soil moisture and aeration beneath pervious and impervious pavements. Journal of Arboriculture 35 (3): 135141. [online] URL: http://www.researchgate. net/publication/259624687

Morgenroth J (2011). Root growth response of Platanus orientalis to porous pavements. Arboriculture and Urban Forestry 37 (2): 45-50. [online] URL: http://www.researchgate.net/pro file/Justin_Morgenroth/post/What_is_the_effic iency_of_the_geophysical_methods_to_map_t ree_root_systems/attachment/59d62f13c49f47 8072egfb51/AS:273579126525953@1442237755 406/download/Published_Copy.pdf

Mueller EC, Day TA (2005). The effect of urban ground cover on microclimate, growth and leaf gas exchange of oleander in Phoenix, Arizona. International Journal of Biometeorology 49 (4): 244-255. - doi: 10.1007/s0o484-004-0235-1 Mukherjee A, Agrawal M (2018). Use of GLM approach to assess the responses of tropical trees to urban air pollution in relation to leaf 
functional traits and tree characteristics. Ecotoxicology and Environmental Safety 152: 4254. - doi: 10.1016/j.ecoenv.2018.01.038

Mullaney J, Lucke T, Trueman SJ (2015a). The effect of permeable pavements with an underlying base layer on the growth and nutrient status of urban trees. Urban Forestry and Urban Greening 14: 19-29. - doi: 10.1016/j.ufug.2014.11. 007

Mullaney J, Lucke T, Trueman SJ (2015b). A review of benefits and challenges in growing street trees in paved urban environments. Landscape and Urban Planning 134: 157-166. doi: 10.1016/j.landurbplan.2014.10.013

Mullaney J, Trueman SJ, Lucke T, Bai SH (2015C). The effect of permeable pavements with an underlying base layer on the ecophysiological status of urban trees. Urban Forestry and Urban Greening 14 (3): 686-693. - doi: 10.1016/j.ufug.20 15.06.008

Noguchi K, Yoshida K (2008). Interaction between photosynthesis and respiration in illuminated leaves. Mitochondrion 8 (1): 87-99. - doi: 10.1016/j.mito.2007.09.003

Pan R, Wang X, Li N (2012). Plant physiology. Higher Education Press, Beijing, China, pp. 69119.

Pathak V, Tripathi BD, Mishra VK (2011). Evaluation of Anticipated Performance Index of some tree species for green belt development to mitigate traffic generated noise. Urban Forestry and Urban Greening 10 (1): 61-66. - doi: 10.1016/ j.ufug.2010.06.008

Reich PB, Oleksyn J, Wright IJ (2009). Leaf phosphorus influences the photosynthesis-nitrogen relation: a cross-biome analysis of 314 species. Oecologia 160: 207-212. - doi: 10.1007/s00442009-1291-3

Scholz T, Hof A, Schmitt T (2018). Cooling effects and regulating ecosystem services provided by urban trees novel analysis approaches using urban tree cadastre data. Sustainability 10 (3): 118. - doi: 10.3390/su10020001

Smith SE, Smith FA (2011). Roles of arbuscular mycorrhizas in plant nutrition and growth: new paradigms from cellular to ecosystem scales. Annual Review of Plant Biology 62: 227-250. doi: 10.1146/annurev-arplant-042110-103846 Song Y, Li F, Wang X, Xu C, Zhang J, Liu X, Zhang $H$ (2015). The effects of urban impervious surfaces on eco-physiological characteristics of Ginkgo biloba: a case study from Beijing, China.
Urban Forestry and Urban Greening 14 (4): 1102-1109. - doi: 10.1016/j.ufug.2015.10.008 Steppe K, Lemeur R (2007). Effects of ring-porous and diffuse-porous stem wood anatomy on the hydraulic parameters used in a water flow and storage model. Tree Physiology 27: 43-52. doi: 10.1093/treephys/27.1.43

Taneda H, Sperry JS (2008). A case-study of water transport in co-occurring ring- versus diffuse-porous trees: contrasts in water-status, conducting capacity, cavitation and vessel refilling. Tree Physiology 28: 1641-1651. - doi: 10.1093/treephys/28.11.1641

Viswanathan B, Volder A, Watson WT, Aitkenhead-Peterson JA (2011). Impervious and pervious pavements increase soil $\mathrm{CO}_{2}$ concentrations and reduce root production of American sweetgum (Liquidambar styraciflua). Urban Forestry and Urban Greening 10 (2): 133-139. - doi: 10.1016/j.ufug.2011.01.001

Volder A, Viswanathan B, Watson WT (2014). Pervious and impervious pavement reduce production and decrease lifespan of fine roots of mature Sweetgum trees. Urban Ecosystems 17 (2): 445-453. - doi: 10.1007/s11252-013-0330-3

Walker AP, Beckerman AP, Gu L, Kattge J, Cernusak LA, Domingues TF, Scales JC, Wohlfahrt G, Wullschleger SD, Woodward FI (2014). The relationship of leaf photosynthetic traits $-V_{\text {cmax }}$ and $J_{\max }$ - to leaf nitrogen, leaf phosphorus, and specific leaf area: a meta-analysis and modeling study. Ecology and Evolution 4 (16): 3218-3235. doi: $10.1002 /$ ece 3.1173

Wan L, Xing Z, Chang X, Liu J, Zhang G (2018). Research on light response curve fitting model of four Chamaenerion plants on the Serzilla Mountains. American Journal of Plant Sciences 9: 1630-1645. - doi: 10.4236/ajps.2018.98118

Wang H, Han L, Xu Y, Niu J (2014). Photosynthetic responses of the heteromorphic leaves in Populus euphratica to light intensity and $\mathrm{CO}_{2}$ concentration. Chinese Journal of Plant Ecology 38(10): 1099-1109. [in Chinese] - doi: 10.3724/SP.J.1258.2014.00104

Wang X, Chen Y, Wang X (2017). Impact of land pavement on photosynthetic characteristics of common greening trees in Beijing, China. Chinese Journal of Applied Ecology 28 (8): 24232430. [in Chinese]

Wang X, Wang X, Su Y, Zhang H (2019). Land pavement depresses photosynthesis in urban trees especially under drought stress. Science of the Total Environment 653: 120-130. - doi: 10.1016/j.scitotenv.2018.10.281

Warren CR, Adams MA (2004). What determines rates of photosynthesis per unit nitrogen in Eucalyptus seedlings? Functional Plant Biology 31 (12): 1169-1178. - doi: 10.1071/FP04115

Weng Q (2012). Remote sensing of impervious surfaces in the urban areas: requirements, methods, and trends. Remote Sensing of Environment 117: 34-49. - doi: 10.1016/j.rse.2011.02. 030

Willis KJ, Petrokofsky G (2017). The natural capital of city trees. Science 356 (6336): 374-376. doi: 10.1126/science.aam9724

Wu FZ, Bao WK, Li FL, Wu N (2008). Effects of water stress and nitrogen supply on leaf gas exchange and fluorescence parameters of Sophora davidii seedlings. Photosynthetica 46 (1): 40-48. - doi: 10.1007/s11099-008-0008-x Yamori W (2016). Photosynthetic response to fluctuating environments and photoprotective strategies under abiotic stress. Journal of Plant Research 129 (3): 379-395. - doi: 10.1007/s10265016-0816-1

Yan Y, Kuang W, Zhang C, Chen C (2015). Impacts of impervious surface expansion on soil organic carbon-a spatially explicit study. Scientific Reports 5 (1): 745. - doi: 10.1038/srep17905

Yang $\mathrm{N}$, Wang $\mathrm{X}$, Cotrozzi L, Chen $\mathrm{Y}$, Zheng $\mathrm{F}$ (2016). Ozone effects on photosynthesis of ornamental species suitable for urban green spaces of China. Urban Forestry and Urban Greening 20: 437-447. - doi: 10.1016/j.ufug.2016.10.014 Ye Z (2010). A review on modeling of responses of photosynthesis to light and $\mathrm{CO}_{2}$. Chinese Journal of Plant Ecology 34 (6): 727-740. [in Chinese]

Zhu M, Xu W, Wen J, Zhu Y, Li Y, Su Y, Zhang Q, Sun RC (2017). Dynamic changes of photosynthetic properties and chemical compositions of Eucommia ulmoides Oliver under two planting models. Industrial Crops and Products 96: 4656. - doi: 10.1016/j.indcrop.2016.11.023

\section{Supplementary Material}

Appendix 1 - Modified rectangular hyperbolic models for light and $\mathrm{CO}_{2}$ response curves and the biochemical model for $\mathrm{CO}_{2}$ response curves.

Link:Wang_2939@supploo1.pdf 